\title{
Proaktif Kariyer Adanmışlığı Davranışları Ölçeğinin Türkçeye Uyarlama ve Doğrulayıcı Faktör Analizi Çalışması
}

\author{
Aziz MUSLU*, Abdülnaim TEMUR**
}

Öz

Denizcilik, zorlu koşulları nedeniyle çalışanların meslekten erken yașta ayrıldığı bir meslektir. Bu duruma etki eden birçok faktör olsa da denizci adaylarının kariyer planlaması yapmaması ve mesleğe olan adanmışlığının olmaması sektör profesyonellerince neden olarak gösterilmektedir. Çalıșmanın amacı, kariyer adanmışlığını ölçen bir ölçeğin uyarlanarak Türkçeye kazandırılmasıdır. Bu çalışmada Hirschi ve arkadaşları tarafından kariyer adanmışlığını ölçmek amacıyla geliştirilmiş olan proaktif kariyer ölçeği denizci adayları üzerinde kullanılmıştır. Araştırma kapsamında, sosyal ağlar ve elektronik posta yoluyla Deniz Ulaștırma İșletme Yönetimi bölümünde öğrenim gören Türkiye genelindeki 281 öğrenciye ulaşılmıştır. Amos 21 programı kullanılarak yapısal eşitlik modeliyle doğrulama çalışması yapılmıștır. Yapılan analiz sonucunda çalıșmada kullanılan ölçeğin model uyum indekslerine göre ölçek alan yazınında kabul edilen yapısal eșitlik modeli uyum değerlerine sahip olduğu görülmüștür. Günümüzde proaktif kariyer adanmışlığı davranışlarının artan öneminden dolayı ölçek uyarlanarak Türkçe literatüre kazandırılmıştır.

Anahtar Kelimeler: Denizcilik, Deniz İșletmeciliği, Kariyer Adanmışlığı, Kariyer Yönetimi, Kariyer Planlama

\section{Adaptation of the Career Engagement Scale that Measures Proactive Career Behavior into Turkish and Confirmatory Factor Analysis Study}

\section{Abstract}

Maritime is a profession where employees leave the profession at an early age due to the difficult conditions. Although there are many factors that affect this situation, seafarers' candidates do not plan their careers and the lack of commitment to the profession is shown by industry professionals as a reason. In this study, a previously developed scale was used to measure the career engagement of seafarers. The reliability and validity studies of the career dedication scale have been applied to the Maritime Transport Management Department students who will work as future captains in the maritime industry. 281 students reached via social networks and e-mail in Turkey. In the results of the analysis, a verification study was carried out with the Amos 21 structural

\section{Özgün Araștırma Makalesi (Original Research Article) \\ Geliş/Received: 13.02 .2020 \\ Kabul/Accepted: 03.07.2020 \\ DOI: https://dx.doi.org/10.17336/igusbd.681944}

* Doç. Dr., Ordu Üniversitesi, Fatsa Deniz Bilimleri Fakültesi, Ordu, Türkiye,

E-posta: azizmuslu@gmail.com ORCID https://orcid.org/0000-0002-3496-1374

${ }^{* *}$ Dr. Öğr. Üyesi, İstanbul Gelişim Üniversitesi, Uygulamalı Bilimler Yüksekokulu, İstanbul, Türkiye,

E-posta: $\underline{\text { naimtemur@gmail.com ORCID https://orcid.org/0000-0001-9802-1587 }}$ 
Aziz Muslu, Abdülnaim Temur, "Proaktif Kariyer Adanmışlığı Davranışları Ölçeğinin Türkçeye Uyarlama ve Doğrulayıcı Faktör Analizi Çalışması”, İstanbul Gelişim Üniversitesi Sosyal Bilimler Dergisi, 8 (1), Nisan 2021, ss. $15-28$.

equation model developed by Hirschi et al. According to the model fit indexes, it has been seen that the structural equation model fit values accepted in the scale literature. The scale has been adapted and brought into the Turkish literature due to the increasing importance of proactive career engagement behaviors.

Keywords: Maritime, Maritime Business, Career Dedication, Career Management, Career Planning

\section{Giriş}

Günümüzde teknolojide yaşanan hızlı gelişmeler tüm sektörlerde istihdam sayılarını azaltırken diğer yandan nitelikli işgücü ihtiyacını arttırmıştır. Bu nedenle klasik kariyer anlayıșının terk edildiği bir sürece girildiğini ifade etmek mümkündür. Klasik kariyer anlayışında çalışma hayatına yeni başlayan adayların terfileri için günümüz şartlarına göre gösterilmesi gereken bilgi birikimi ve nitelik şartlarının gerçekleșmesi beklenmemekteydi. Bilgi sermayesinin önemli bir noktaya gelmesi, insan kaynağının proaktif bir șekilde her gün kendini geliștirme zorunluluğunu ortaya çlkarmıștır. Günümüzde işletmelerin ihtiyacı olan nitelikli iş gücü, yaşanan hızlı değişimlere ayak uydurabilen, bunu kariyer planlaması doğrultusunda gerçekleștiren bireylerdir. Proaktif kariyer davranışları günümüzün kariyer ortamında giderek daha önemli hale gelmektedir (Hirschi ve diğerleri, 2013). Kariyer planlaması ile doğru hedeflere ulaşan bireyler iş bulma ve yükselme olanaklarını yakalayabilmektedir. Günümüzde, klasik kariyer anlayıșı yerine proaktif kariyer davranışları sergileyerek, kariyer gelişiminde nitelik ve becerilerin geliştirilmesi her sektörde olduğu gibi denizcilik sektöründe de önem kazanmıştır. Nitelikli iş bulmak ve o işi yaşam boyu sürdürebilmek proaktif kariyer yönetimini denizcilik sektöründe de zorunlu kılmaktadır. Diğer sektörlere kıyasla gelişmelerden daha geç etkilenen denizcilik sektörü endüstri 4.0 devrimi ile daha hızlı bir değişim süreci içine girilmiştir. Gemi başına asgari donatma yönetmeliğine göre istihdam edilen gemi adamı sayısı her geçen gün azalmaktadır. Dünya Deniz Ticaret Odası'nın Başkanı Esben Poulsson (Poulsson, 2018) yapılan röportajında 1966'da 9.000 dwt ton bir gemide 40 mürettebat çalıştığını günümüzde 14.000 TEU kapasiteli dev bir konteyner gemisinde aynı sayıda mürettebatın çalıştığını ifade etmiştir. Bu durum her geçen gün gemi adamları emek piyasasında rekabetin arttığını göstermektedir. Bu nedenle denizcilik okullarında eğitim gören öğrenciler kariyerlerini en verimli şekilde oluşturmak için proaktif bir kariyer planlama davranışı göstermeleri gerekmektedir. Türkiye, gemi adamı ihraç eden bir ülke olmayı planlamaktadır. Sadece nitelikli eleman yetiştirmek, yetiștirilen nitelikli gemi adamlarının istihdamını sağlayamamaktadır. Denizcilik sektöründe, gemi adamları iş piyasasına girecek olan mezunların klasik kariyer planlamasının dışına çıkarak, proaktif kariyer davranışları sergilemeleri gerekmektedir. Her bir öğrenci için kariyer planlama süreci kendi deneyimlerine, ilgilerine, yeteneklerine ve değerlerine göre farklılık gösterir. Öğrencilerin eğitimlerinin ilk veya son döneminde kariyer hedeflerine yönelik farkındalıkları, geleceklerini yönlendirmede önemli bir unsurdur (Cevher, 2015). Kariyer çoğu birey tarafından sadece bir meslek seçmek ve meslekte yükselmek olarak anlaşılsa da, aslında bireyin tüm yaşam alanlarını etkileyen inişler ve çıkışlarla geçen bir yaşam yapılandırma sürecidir (Kalafat, 2020). Bütün bu nedenlerle meslek adaylarının, kariyer davranıș ve yönelimleri ayrıca önemlidir.

Kariyer yönetimi ile ilgili alan yazınında yapılan çalışmalar incelendiğinde kariyer adanmışlığına aracılılık eden psikoloji, tutum, davranışlar ve kişilik faktörleri konusunda aşağıdaki çalışmalara ulaşılmıştır. Kariyer adanmışlığı gelecek planlaması ve bu yöndeki davranışlar (Savickas ve ark., 2009); iş arama yöntemleri (Koen ve ark., 2010); gerçekçi ve planlı kararlar vermek (Ebberwein ve ark., 2004); kariyer engelleriyle baş etme (Niles 
Aziz Muslu, Abdülnaim Temur, "Proaktif Kariyer Adanmışlığı Davranışları Ölçeğinin Türkçeye Uyarlama ve Doğrulayıcı Faktör Analizi Çalışması”, İstanbul Gelişim Üniversitesi Sosyal Bilimler Dergisi, 8 (1), Nisan 2021, ss. $15-28$.

ve Harris-Bowlsbey, 2013) ve engelleri avantaja dönüştürme becerileri (Savickas ve Porfeli, 2012); kariyer yönetimi (Savickas, 2005); kariyer başarısı (Hirschi, 2010); kariyer doyumu (Zacher, 2014); iyi iş olanakları yakalama (Klehe ve ark., 2012); hızlıca gelișen iș hayatında meta-yeteneklerin kazanılması (Hall ve Mirvis, 1995); iş stresi ve mutluluk seviyesi (Ferreira, 2012).

Kim ve arkadaşları tarafından (2014) yapılan çalışmada, üniversite öğrencilerinin planlanan etkinlik becerilerinin kariyer katılımı, kariyer kararı öz yeterliği ve kariyer kararı kesinliği arasındaki ilișkileri nasıl etkilediğini incelemiştir. 217 Koreli lisans öğrencisi örnekleminde aracılık ilişkisi analiz edilmiştir. Sonuçlar, kariyer kararının özyeterlik, kariyer katılımı ve kariyer kararı kesinliği arasındaki ilişkiye aracılık etmiştir. Ayrıca, kariyer kararı özerkliği yoluyla kariyer katılımının kariyer kararı üzerindeki olumlu dolaylı etkisi, planlanan etkinlik becerileri arttıkça güçlendirilmiştir. Sonuç olarak, üniversite öğrencilerinin kariyeri angajman ve beklenmedik kariyer firsatlarını keşfetmek için yeterli planlanmış beceriye sahip olduklarında, kariyer kararları ile kariyer kararlarının kesinliğini güçlendirdiği tespit edilmiştir.

2016 yılında Parisa ve Samaneh (2016) tarafından kariyer adaptasyonunda, kişilik ve kariyer adanmışlığının aracı rolü incelenmiştir. Sonuç olarak, bu araștırma kariyer adaptasyonun kişilik boyutları ve öğrencilerin kariyer adanmışlığı alt boyutları arasındaki ilişkiye aracılık ettiğini açıkça göstermiştir. Bu çalışmanın sonuçları öğrenciler arasında kariyer adanmışlığı ile ilgili literatüre katkıda bulunmaktadır (Nilforooshan ve Salimi, 2016).

Türkçe olarak kariyer adanmışlığına yönelik geliştirilmiş bir ölçek çalışmasına rastlanılmamıştır. Kariyer adanmışlığı davranışını ölçmek amacıyla Hirschi ve arkadaşları da (2014) yılında "Career Engagement Scale: Development and Validation of a Measure of Proactive Career Behaviors" isimli Kariyer Davranışlarını Ölçen Kariyer Adanmışlığı ölçeği oluşturmuşlardır. Bu çalışmanın Türkçeye uyarlanmasının en önemli nedeni özgünlügü̈, yazarların alan yazınında yetkinliği ve ifadelerin net ve anlaşılır olmasıdır. Ölçek ifadeleri denizcilik, işletme ve eğitim planlama alanlarında çalışan uzmanların görüşleri alınarak düzenlendi. Ölçek ifadelerinin Türkçeleștirilmesinde dil bilimcilerinin tavsiyeleri ile önerilen değişiklikler yapılmıştır. Ölçeğin yapısal geçerliliğinin tespiti ve doğrulamak amacıyla doğrulayıcı faktör analizi ile araştırma gerçekleştirilmiștir. Çalışmada kariyer adanmışlığı ölçeği doğrulama çalışması yapılırken Türkiye'de deniz ulaştırma işletme yönetimi mühendisliği öğrencilerine uygulanmıştır.

\section{Araştırmanın Amacı}

Yapılan araştırma sonucunda denizcilik mesleğinde kariyer yönetimine yönelik, Türkiye alan yazınında benzer bir çalışma yapılmamıştır. Denizcilikte kariyer yönetimi ile dolaylı ilişkili olan yayınlar mevcuttur. $\mathrm{Bu}$ nedenle "Career Engagement Scale: Development and Validation of a Measure of Proactive Career Behaviors" adlı çalışmanın ülkemiz denizcilik sektörüne ve diğer mesleklere kazandırılması için geçerliliğinin ve güvenilirliğinin kabul edilebilir düzeyde olup olmadığı araştırılmıştır. Ölçeğin geçerliliğinin ve güvenilirliğinin kabul edilebilir düzeyde olup olmadığı araştırılmıştır. Proaktif kariyer davranışını ölçen bir ölçek olarak kariyer adanmışlığı ölçeği Amos 21 programında doğrulanmıştır.

\section{Araştırmanın Yöntemi}

Metodolojik bir araştırma olarak kariyer adanmışlığı ölçeği Amos 21 yapısal eşitlik modeli ile doğrulanmıştır. Araştırma elektronik posta ve sosyal medya aracılı̆̆ıyla Türkiye'nin farklı yerlerinden Denizcilik Fakültesi Deniz Ulaştırma İşletme Mühendisliği 
Aziz Muslu, Abdülnaim Temur, "Proaktif Kariyer Adanmıșlığı Davranıșları Ölçeğinin Türkçeye Uyarlama ve Doğrulayıcı Faktör Analizi Çalışması”, İstanbul Gelişim Üniversitesi Sosyal Bilimler Dergisi, 8 (1), Nisan 2021, ss. $15-28$.

bölümü 281 öğrenciye uygulanmıș, olasılıksız örneklem yöntemi ile veri toplanmıştır. Ölçek çalışmaları için faktör analizi oluşturulurken örneklem büyüklüğü ölçek ifade sayısının 5-10 katından daha az olması önerilir (Akgül, 1997). Ölçeğin uygulandığı sayı alan yazınına göre önerilen rakamın üstündedir.

Veriler iki bölümde toplanmıștır;

1. Deniz Ulaștırma İșletme Mühendisliği öğrencilerinin sosyal, demografik ve meslekle ilgili özelliklerini belirten altı madde soru sorulmuştur.

2. Bölüm kariyer adanmışlık ölçeğine ait dokuz madde ifade Türkçeleștirilerek, beşli likert yöntemi ile 1. Kesinlikle katılmıyorum - 5. Kesinlikle katılıyorum şeklinde ölçek formu düzenlenmiştir.

\section{Kariyer Yönetimi ve Kariyer Adanmışlığı}

Kariyer, bireyin işinden beklentilerini, duygu ve arzularını gerçekleştirebilmesi için örgüt tarafından eğitilmesi sonucu bilgi ve becerilerini arttırması ve kişisel azmi ile mesleki hayatında ilerleyebilmesidir. Bir başka ifade ile bir kișinin iș hayatı boyunca iș ile ilgili edindiği tecrübeleridir (De Cenzo ve Robins, 1996, s. 266). Başarının tesadüf olmadığı ve kariyerin yönetilmesi ile başarının geldiği iş hayatının temel kurallarından biri haline gelmiştir. Kariyer yönetimini birey olarak iş gören ve onu istihdam eden örgüt açısından ayrı ayrı değerlendirmek gerekir. Bireysel ve örgütsel açıdan olmak üzere iki boyuttan değerlendirilir (Okakın, 2008). Şöyle ki; Birey açısından kariyer yönetimi yaşamı boyunca hedeflerini gerçekleştirebilmek için gerekli gördüğü faaliyetleri planlaması ve uygulamaya koyması olarak tanımlanabilir. Çalışma yaşamında yaşanan gelişmeler kariyer yönetimi hususunda geçmișe oranla bireye daha fazla sorumluluk yüklemektedir. Geçmişte piramit tipi bürokratik organizasyon yapılanmalarında kıdem ile birlikte gelmekte olan terfi günümüzde çalışanın yetenekleri, nitelikleri ve kariyer adanmışlığı ile birlikte gerçekleşmektedir.

Kariyer kavramının gelişimine baktığımızda, 1900'lü yılların başında atılmaya başlanan ve ortalarına doğru hızla gelişen bürokratik tipi örgütlerin varlığına dayandırmak mümkündür. Söz konusu örgütler klasik üçgen şeklindeki organizasyon yapıları ile yüksek performansa sahip çalışanlara yükselme imkânları sunabilmekte ve uzun vadeli istihdam güvencesi sağlayabilmektedir (Peiperl ve Baruch, 1997, s. 8). 1980'li yıllar süresince o dönemdeki örgütlerin de bu yaklaşımı desteklemeleriyle geleneksel kariyer yaklaşımı istihdam sistemlerine hâkim olmuştur (Sullivan, 1999, s. 457). Bu yaklaşıma göre kariyer başarısı, terfi ve ücretlerdeki artış ile ölçülen ve örgütlerce belirlenen bir süreçtir. Günümüzde ise bürokrasiye dayalı kariyer sisteminden, yeni, etkin ve sınırsız kariyer anlayıșına geçilmiştir (Baruch, 2004, s. 38). İşletmelerin yaşam boyu istihdam imkânları sunmaları yok denilebilecek noktaya gelmiştir. Kültürel farklılıklardan dolayı Asya ülkelerinde talep gören yaşam boyu istihdam olanağı işletmelerin yaşadığı ekonomik krizler nedeni ile sürdürülemeyecek bir insan kaynakları politikası olmuştur. Bu nedenle kariyer yönetiminde bürokratik kariyer yönetiminden daha çok bireye sorumluk yükleyen çeşitli kariyer yaklaşımları ortaya çıkmıștır. Esnek Kariyer Yaklaşımı anlayıșı, hiyerarşik olan organizasyon yapısının yatay bir yapıya tahvil edilmesi, iş tanımlarının çeşitlendirilmesi ve zenginleştirilmesi, çalışmaların projeye dayalı olarak yapılması, sorumlulukların arttırılması sağlanarak çalışanların yetkilendirilmesini içerir (Aytaç, 2005, s. 242). Tek bir örgüt içerisinde olmadan farklı örgütler arasındaki hareketliliği içeren, kariyer olgusunun geleneksel kariyer prensiplerinden ve işletmeden bağımsız olarak ele alınmasını içeren Sınırsız Kariyer Yaklaşımı (Erdoğmuş, 2003, s. 162), bireylerin özellikle iş yaşamlarının son dönemlerine hâkim olan Portföy Kariyer Yaklaşımı (Handy, 1998, s.156) ile kişinin psikolojik olarak 
Aziz Muslu, Abdülnaim Temur, "Proaktif Kariyer Adanmıșlığı Davranıșları Ölçeğinin Türkçeye Uyarlama ve Doğrulayıcı Faktör Analizi Çalışması”, İstanbul Gelişim Üniversitesi Sosyal Bilimler Dergisi, 8 (1), Nisan 2021, ss. $15-28$.

başarmak amacıyla kariyerini kendisinin çizdiği, esnek yapıdaki, uygulanabilir Çok Yönlü Kariyer Yaklaşımı (Hall, 2002, s. 24) olarak sınıflandırılması mümkündür.

Kariyer geliştirme planları da kendi içinde işletmelerin çalışanları için belirlediği kariyer planları ve bireylerin beklentisini ifade eden kariyer planı olmak üzere iki farklı aşamada değerlendirilmelidir. Bu ikili ayrımda ișletmelerin planlarına kariyer yönetimi, bireylerin planlamalarına ise kariyer planlama denilmektedir. Ayrıca "Kariyer yolu ise bir kişinin kariyerini oluşturan birbirini takip eden işlerdir" (Okakın, 2009). Kariyer yolu meslek seçimi ile başlamaktadır. Meslek seçimi ve eğitim süreci kariyer üst aşamalarında oluşacak başarıyı doğrudan etkilemektedir. Meslek eğitimi aşamasında kariyer adanmışlığı kariyer planlarının gerçekleştirilmesini sağlamaktadır.

Kariyer geliștirme, bireylerin kendilerine has problem, iş ve görevler bütünü ile ayrılabilecek basamaklar dizisi süresince sürekli kendilerini geliștirme etkinlikleri olarak tanımlanmaktadır. Bir diğer tanıma göre kariyer geliştirme, çalışanların kabiliyetlerinin geliştirilmelerine, değerlendirmelerine ve genişletmelerine olanak vererek kariyer amaçlarını ve hedeflerini gerçekleștirmeleri için elverişli ortamı hazırlamak olarak ifade edilmektedir (Kozak, 2009, s. 24). Bu yönüyle kariyer geliștirme ve planlama kariyer adanmışlığı ile geliștirilebilecek bir süreçtir. Kariyer planlamada; ferdin seçeneklerin, fırsatların ve sonuçlarının farkına varması, kişisel kariyeri ile ilgili hedefleri tayin etmesi ve bu hedeflerine ulaşmak için yönünü saptayıp zaman ve mekân planlarını yapmasını sağlayacak şekilde iș, eğitim ve diğer gelişimsel etkinliklerin programlanmasıdır (Ersen, 1996, s. 112).

Kariyer planlaması ve kariyer yönetimi çalışan bireyin kişisel olarak oluşturması gereken bir husus olarak algılanmaktadır. Kariyer planlaması ve yönetimi organizasyonların başarılı olması, bu başarıları istikrarlı olarak devam ettirilmesi için gereklidir (Muslu, 2008, s. 78). Kariyer planlaması yapılırken çalışanın kariyer hedeflerine ulaşabilmesi için işletme yönetimi tarafından desteklenmelidir. Kariyer bireysel kararlarla şekillenen bir husus olsa bile işletmelerin kariyer geliştirme için çalışanlarına uygun eko sistemi oluşturmaları gerekmektedir.

Günümüz işletmelerinin ihtiyaç duydukları nitelikli ve yetişmiş personeli temin etmede çektikleri güçlükler nedeniyle çoğu zaman kendi bünyelerinde eğitim programları geliştirip uygulamaya başlamışlardır. Bundan amaç nitelikli personelin organizasyonda daha uzun süre kalmasını sağlamaktır (Yıldırım, 2000, s. 435). Yeni kuşak çalışanların bağlılık düzeylerinin düşük olması günümüz işletmelerine ayrıca sorumluluk yüklemektedir. Yöneticiler koçluk ve mentorluk yaparak Y kuşağının gelecek vizyonlarının kurumla eş güdümlü olarak oluşturulmanın yollarını aramak zorundadırlar (Muslu, 2017, s.483). Yeni kariyer yaklaşımları ile birlikte, çalışan adayı olarak kariyer yönetiminin eğitim sürecinde başlaması gereken daha çok bireysel bir süreç olarak algılanmaktadır. Bu durum iş yaşamının rekabetçi koşullarından kaynaklansa bile kurumlar kariyer adanmışlığı olan adayları ișe alarak yatırım yapmak istemektedir. Örgüte ve mesleğe bağlılık düzeyi düşük çalışanların kariyer gelişimi için yatırım yapmak istememektedir.

Kariyere adanmışlık, bireyin farklı kariyer tutumları göstererek proaktif bir şekilde kariyerini geliştirme düzeyi şeklinde tanımlanmaktadır (Hirschi, Freund ve Herrmann, 2014). Kariyer adanmışlığının, işe adanmışlık, kariyere bağlılık, kariyer adaptasyonu ve kariyer güdülenmesi gibi kavramlardan farklı bir kavramı temsil etmektedir. Bu kavramlar bir tutumu ifade ederken, kariyer adanmışlık ise davranışlara işaret etmektedir (Nilfooroshan ve Salimi, 2016, s. 2). Kariyer adanmışlık davranışı iş tutumlarını etkilemektedir. Kariyer adanmışlıkla ilgili yapılan çalışmalara bakıldığında, duygusal denge, kariyer kararı alma yeterliliği (Rogers, Creed ve Glendon, 2008), sosyal destek ve olumlu duyguların (Hirshi ve Freund, 2014) kariyer adanmışlığını olumlu yönde etkilediğini söylemek mümkündür. 
Proaktif davranış, stratejik düşünce sistematiği ile hareket ederek gelecek hakkında kararlar almayı gerektiren planlı bir davranış biçimidir. Kariyer kavramı ile doğrudan ilişkilidir. Çalışma hayatında yaşanan hızlı değişim sürecinde proaktif bir kariyer planlaması çalışanlar için zorunluluk haline gelmiştir. Geleceğin öngörülememesi beklenen gelişmelerde beklenmeyen sonuçların çıkması kariyer yönetiminde proaktif davranış biçimlerini zorunlu kılmıştır. Proaktivite kavramı uzun döneme odaklanarak, karşılaşılacak fırsat ya da tehditleri önceden sezerek bunlara göre pozisyon almaktır. Bir başka deyişle firsatları ve tehditleri önceden görerek birilerinin bir şey demesine gerek kalmadan, çalışanın kendi kendine erken davranmasıdır (Grant \& Ashford, 2008: 3-34).

Parker vd. (2006) proaktif davranışı; "bireyin kendisinin başlattığl, karşılaşmış olduğu vaziyeti değiştirmeyi veya geliştirmeyi amaçlayan ileriye çevrili faaliyetleri" şeklinde tanımlamaktadırlar. Proaktif kişiler, girişken, fırsatları önceden gören ve harekete geçen, inisiyatif gösteren ve anlamlı bir değișim ve hedeflerine ulaşana kadar kararlılık ile gayret gösteren, diğer işçilerden ayrışan kişilerdir (Bateman ve Crant, 1993; Gupta ve Bhawe, 2007). Proaktif davranıș özelliklerine sahip olmak olaylar, olgular ve gelişmeler karșısında kısa vadeli ani kararlar almak yerine orta ve uzun dönemli kararlar almayı gerektirmektedir. Proaktif kariyer yönetiminde meslekteki ve sektörel gelişmelerin takip edilmesi oldukça önemlidir. Proaktif bireylerin, kariyerle ilgili değişikliklerle etkin olarak ilgilenmeleri, gelişme fırsatlarını keşfetmeleri ve kariyer gereksinimleri için çalışma platformu yaratmaları kuvvetle muhtemeldir. (Bateman ve Crant, 1993). Proaktif bireyler, iş hayatlarında ve kariyer evrelerinde daha fazla bağımsız hareket etme ve karar alma yeteneğine sahiptirler (Siebert vd., 1999). Proaktif bireyler kariyerlerini tesadüflere bırakmak yerine kendi kararlarını almaları sebebiyle iş hayatında başarılı ve mutlu olacaklardır.

Yapılan araștırmalar göstermektedir ki; proaktif kișilerin çalıșma yaşamı ve kariyer yönetimi konusunda oldukça başarılı olmuşlardır. Proaktif kişilerin iş bulmada ve kariyer uyumluluğunu sağlamada başarılı oldukları tespit edilmiştir (Brown vd., 2006; Seibert vd., 1999). Seiber ve arkadaşlarının (1994) yaptıkları çalışmada, kişilerin, nesnel olan maaș ve terfi gibi kariyer başarılarını ve kariyerleri ile ilgili doyum ve tamamlanmışlık gibi hislerini ifade eden öznel kariyer başarısı ile proaktif kişilik arasında anlamlı bir ilişki vardır (Seiber vd.,1994: 416-427). Barrick ve Mount'ın (1991) yaptığı çalışmada, proaktif bireylerin ısrarcı oldukları ve iş performansıyla proaktif kişilik arasında ilişki olduğunu saptamışlardır. (Barrick ve Mount, 1993: 111-118). Thompson (2005) yaptığı çalışmada, proaktif kişilerin kariyer hedeflerine ulaşmada daha etkin olduklarını belirtmiştir.

Tüm sektörler için proaktif kariyer adanmışlığı davranışları gösteren bireyler tercih edilmek istenmektedir. Yașam boyu istihdam olanaklarının olmaması bireylerin kariyerlerini proaktif şekilde yönetmesini zorunlu kılmaktadır. Denizcilik işi, yapısı gereği yaşam boyu istihdam için uygun koşullar barındırmamaktadır. Denizcilikte her dönem kariyer yönetimi ve planlaması, kurumdan bağımsız oluşturulan bireysel bir süreçtir. Yaşanan hızlı değişim ve denizcilik emek piyasalarındaki rekabet kariyer adanmışlığını daha fazla zorunlu kılmaktadır. Krizler ve hızlı değişimler, kimi zaman fırsatları ve tehditleri de beraberinde getirmektedir. Günümüzde Proaktif kariyer adanmışlığı, fırsatları yakalamak ve tehditlerden korunmak için oldukça önemlidir. Görülen bu gelişmeler neticesinde, proaktif kariyer adanmışlığını ölçen Hirschi ve arkadaşlarının (2014) oluşturduğu ölçek çalıșması deniz ulaștırma ișletme mühendisliği öğrencilerine uygulanarak Türkçeye uyarlanmıştır. 


\section{Ölçek Katılımcılarının Betimsel İstatistikleri}

Tablo 1. DUì Öğrencilerinin Bölge Olarak Doğum Yeri

\begin{tabular}{|c|c|c|c|c|}
\hline & Frekans & Oran & Geçerli Oran & Ardışı toplam \\
\hline Akdeniz & 34 & 12,1 & 12,1 & 12,1 \\
\hline Doğu ve Güneydoğu Anadolu & 20 & 7,1 & 7,1 & 19,2 \\
\hline Ege & 39 & 13,9 & 13,9 & 33,1 \\
\hline İç Anadolu & 38 & 13,5 & 13,5 & 46,6 \\
\hline Karadeniz & 44 & 15,7 & 15,7 & 62,3 \\
\hline Marmara & 106 & 37,7 & 37,7 & 100,0 \\
\hline Total & 281 & 100,0 & 100,0 & \\
\hline
\end{tabular}

Tablo 2. DUiM Öğrencisinin Sınıfı

\begin{tabular}{|c|c|c|c|c|}
\hline & Frekans & Oran & Geçerli Oran & Ardışık Toplam \\
\hline & 1 &, 4 &, 4 &, 4 \\
\hline 1.sınıf & 57 & 20,3 & 20,3 & 20,6 \\
\hline 2. sınıf & 63 & 22,4 & 22,4 & 43,1 \\
\hline 3.sınıf & 77 & 27,4 & 27,4 & 70,5 \\
\hline 4.sınıf & 43 & 15,3 & 15,3 & 85,8 \\
\hline Hazırlık & 40 & 14,2 & 14,2 & 100,0 \\
\hline Total & 281 & 100,0 & 100,0 & \\
\hline
\end{tabular}

Tablo 3. DUIM Öğrencilerinin Mezun Olunan Lise Programı

\begin{tabular}{|c|c|c|c|c|c|}
\hline \multicolumn{2}{|c|}{} & Frekans & Oran & $\begin{array}{c}\text { Geçerli } \\
\text { Oran }\end{array}$ & $\begin{array}{c}\text { Ardişık } \\
\text { toplam }\end{array}$ \\
\hline \multirow{4}{*}{ Valid } & $\begin{array}{c}\text { Anadolu Lisesi veya Fen } \\
\text { Lisesi }\end{array}$ & 140 & 49,8 & 49,8 & 49,8 \\
\cline { 2 - 6 } & Askeri Lise & 3 & 1,1 & 1,1 & 50,9 \\
\cline { 2 - 6 } & Düz Lise & 110 & 39,1 & 39,1 & 90,0 \\
\cline { 2 - 6 } & İmam Hatip Lisesi & 3 & 1,1 & 1,1 & 91,1 \\
\cline { 2 - 6 } & Meslek Lisesi & 25 & 8,9 & 8,9 & 100,0 \\
\hline
\end{tabular}


Tablo 4. DUİM Öğrencilerinin Staj Yapma Durumları

\begin{tabular}{|c|c|c|c|c|}
\hline & Frekans & Oran & Geçerli Oran & Ardışık toplam \\
\hline & 3 & 1,1 & 1,1 & 1,1 \\
\hline Evet & 111 & 39,5 & 39,5 & 40,6 \\
\hline Hayır & 167 & 59,4 & 59,4 & 100,0 \\
\hline Total & 281 & 100,0 & 100,0 & \\
\hline
\end{tabular}

Tablo 5. Denizde Çalışmayı Planladıkları Yıllara Göre Tercihleri

\begin{tabular}{|c|c|c|c|c|}
\hline & Frekans & Oran & Geçerli Oran & Ardışık toplam \\
\hline & 2 &, 7 &, 7 &, 7 \\
\hline 1-5 Yıl & 18 & 6,4 & 6,4 & 7,1 \\
\hline $\mathbf{1 0 - 1 5}$ Yıl & 2 &, 7 &, 7 & 7,8 \\
\hline $\mathbf{1 5 - 2 0}$ Yıl & 98 & 34,9 & 34,9 & 42,7 \\
\hline 5-10 Yıl & 94 & 33,5 & 33,5 & 76,2 \\
\hline Emekliye ayrılana kadar & 67 & 23,8 & 23,8 & 100,0 \\
\hline Total & 281 & 100,0 & 100,0 & \\
\hline
\end{tabular}

Tablo 6. Çalışmayı Planladıkları Gemi Tipleri

\begin{tabular}{|c|c|c|c|c|c|}
\hline & \multirow{2}{*}{\begin{tabular}{|l|} 
Frekans \\
10
\end{tabular}} & \multirow{2}{*}{$\begin{array}{l}\text { Oran } \\
3,6\end{array}$} & \multirow{2}{*}{\begin{tabular}{|l|} 
Geçerli \\
Oran \\
3,6
\end{tabular}} & \multirow{2}{*}{$\begin{array}{l}\text { Ardişık } \\
\text { toplam } \\
3,6\end{array}$} \\
\hline \multirow{8}{*}{ Valid } & & & & & \\
\hline & Akaryakıt veya Kimyasal Tanker & 48 & 17,1 & 17,1 & 20,6 \\
\hline & $\begin{array}{l}\text { Akaryakit veya Kimyasal Tanker, } \\
\text { Ham Petrol Tankeri }\end{array}$ & 21 & 7,5 & 7,5 & 28,1 \\
\hline & $\begin{array}{l}\text { Akaryakıt veya Kimyasal Tanker, } \\
\text { RO-RO- RO/PAX - RO-LA veya Yolcu }\end{array}$ & 1 & 4 & 4 & 28,5 \\
\hline & $\begin{array}{l}\text { Genel Kargo /Kuru Yük Handysize } \\
\text { ve üstü }\end{array}$ & 118 & 42,0 & 42,0 & 70,5 \\
\hline & $\begin{array}{l}\text { Genel Kargo /Kuru Yük Handysize } \\
\text { ve üstü, Akaryakıt veya Kimyasal } \\
\end{array}$ & 6 & 2,1 & 2,1 & 72,6 \\
\hline & $\begin{array}{l}\text { Genel Kargo /Kuru Yük Handysize } \\
\text { ve üstü, Akaryakıt veya Kimyasal } \\
\text { Tanker, Ham Petrol Tankeri }\end{array}$ & 1 & ,4 & 4 & 73,0 \\
\hline & $\begin{array}{l}\text { Genel Kargo /Kuru Yük Handysize } \\
\text { ve üstü, Ham Petrol Tankeri }\end{array}$ & 5 & 1,8 & 1,8 & 74,7 \\
\hline
\end{tabular}


Aziz Muslu, Abdülnaim Temur, "Proaktif Kariyer Adanmıșlığı Davranıșları Ölçeğinin Türkçeye Uyarlama ve Doğrulayıcı Faktör Analizi Çalışması”, İstanbul Gelişim Üniversitesi Sosyal Bilimler Dergisi, 8 (1), Nisan 2021, ss. 15-28.

\begin{tabular}{|l|l|l|l|l|l|}
\hline & $\begin{array}{l}\text { Genel Kargo /Kuru Yük Handysize } \\
\text { ve üstü, RO-RO - RO/PAX - RO-LA } \\
\text { veya Yolcu Gemisi }\end{array}$ & 6 & 2,1 & 2,1 & 76,9 \\
\hline Ham Petrol Tankeri & 15 & 5,3 & 5,3 & 82,2 \\
\hline $\begin{array}{l}\text { Ham Petrol Tankeri, R0-RO- } \\
\text { RO/PAX- RO-LA veya Yolcu Gemisi }\end{array}$ & 1 &, 4 &, 4 & 82,6 \\
\hline Konteyner Gemisi & 5 & 1,8 & 1,8 & 84,3 \\
\hline $\begin{array}{l}\text { RO-RO- RO/PAX- RO-LA veya Yolcu } \\
\text { Gemisi }\end{array}$ & 44 & 15,7 & 15,7 & 100,0 \\
\hline Total & 281 & 100,0 & 100,0 & \\
\hline
\end{tabular}

\section{Proaktif Kariyer Davranışlarını Ölçen Kariyer Adanmışlığı Ölçeğinin Doğrulayıcı Faktör Analizi (DFA)}

Tek boyutlu ve toplam 9 maddeden oluşan proaktif kariyer davranışlarını ölçen kariyer adanmışlığı ölçeğinin tek faktörlü yapısı AMOS 21 programı kullanılarak test edilmiştir. Ölçeğin doğrulayıcı faktör analizi sonucu (DFA) ile elde edilen uyum iyiliği değerleri aşağıdadır. Ayrıca SPSS 21 programında 9 ifadeli ölçeğin Cronbach's Alpha katsayısı 0,840 çıkarak iyi derecede güvenilir olduğu görülmüştür.

Tablo 7. Kariyer Adanmışlık Ölçeği Model Uyum İndeksleri

\begin{tabular}{|c|c|c|}
\hline Model uyum indeksleri & Model & Kabul edilebilir indeksler \\
\hline X2/sd & 3,809 & $0<\mathrm{X} 2 / \mathrm{sd}<5$ \\
\hline CFI & 0,906 & $0,90 \leq \mathrm{CFI} \leq 1,0$ \\
\hline GFI & 0,921 & $0,90 \leq \mathrm{GFI} \leq 1,0$ \\
\hline RMSEA & 0,1 & $0,00 \leq \mathrm{RMSEA} \leq 0,10$ \\
\hline
\end{tabular}

GFI, AGFI'den elde edilen katsayının 0,85 üzerinde olması iyi uyumu işaret etmektedir (Cole, 1987). RMSEA değerinin 0.10 değerinden küçük olması ve $\chi 2 / \mathrm{df}^{\prime}$ in oranının ise 2-5 arasında olması iyi uyumu göstermektedir (Jöreskog ve Sörbom, 2001). Bu değerlere sahip olan ölçeğin Path diyagramı Şekil 1'de verilmektedir. 
Şekil 1. Kariyer Adanmışlığı Ölçeği Path Diyagramı

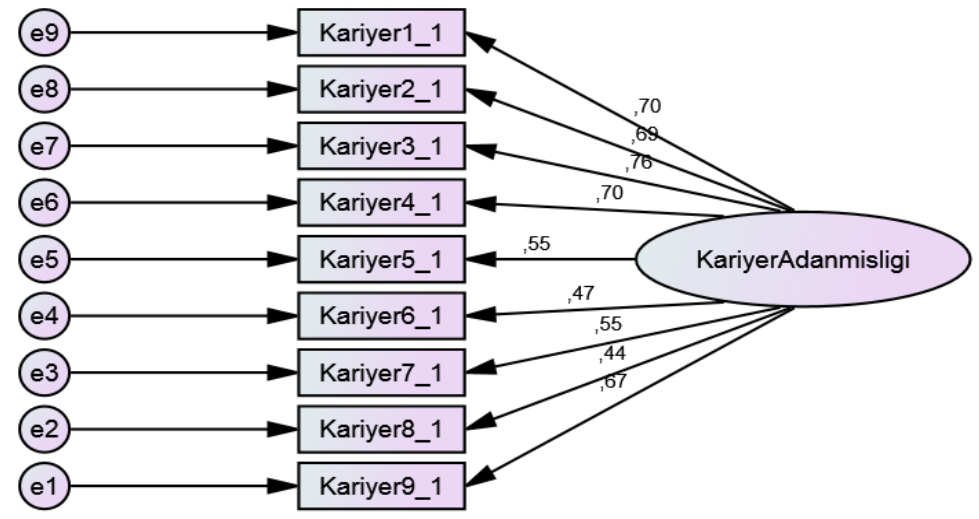

Model uyum indekslerine göre ölçek doğrulanmıştır. Yapılan araştırmada elde edilen bu sonuçlar ile verilerin kariyer adanmışlığı ölçeğinin öngörülen kurumsal yapısı ile uyumlu olduğunu göstermiştir.

Tablo 8. Proaktif Kariyer Davranışlarını Ölçen Kariyer Adanmışlığı Ölçeğinin İfadeleri

\begin{tabular}{|l|l|}
\hline No & Kariyer adanmışlık ölçeği ifadeleri \\
\hline $\mathbf{1}$ & Aktif olarak profesyonel geleceğimi tasarlamaya çalışırım. \\
\hline $\mathbf{2}$ & Kariyer amaçlarıma ulaşmak için çeşitli girişimlerde bulunurum. \\
\hline $\mathbf{3}$ & Kariyer gelişimim ile ilgilenilirim. \\
\hline $\mathbf{4}$ & Gelecekteki kariyerim için planlar ve hedefler geliştiririm. \\
\hline $\mathbf{5}$ & $\begin{array}{l}\text { Kişisel değerlerim, ilgi alanlarım yeteneklerim ve zayıf yönlerim hakkında } \\
\text { gerçekten düşünürüm. }\end{array}$ \\
\hline $\mathbf{6}$ & $\begin{array}{l}\text { İstediğim iş alanındaki işverenler, mesleki gelişim fırsatları veya iş piyasası } \\
\text { hakkında bilgi toplarım. }\end{array}$ \\
\hline $\mathbf{7}$ & $\begin{array}{l}\text { Bana profesyonel olarak yardımcı olabilecek kişilerle temaslar kurarım veya } \\
\text { temaslarımı sürdürürüm. }\end{array}$ \\
\hline $\mathbf{8}$ & $\begin{array}{l}\text { Kariyerimi desteklemek için ekstra eğitim, öğretim veya diğer etkinliklere } \\
\text { gönüllü olarak katılırım. }\end{array}$ \\
\hline $\mathbf{9}$ & $\begin{array}{l}\text { Profesyonel olarak ilerlememe yardımcı olacak görevler veya pozisyonlar } \\
\text { üstlenirim. }\end{array}$ \\
\hline
\end{tabular}

\section{Sonuç}

Kariyer yönetimi insan kaynakları yönetiminin yedi temel fonksiyonundan birisidir. Kariyer yönetimi organizasyonların tek taraflı yönetebilecekleri bir süreç değildir. Bu noktada çalıșanların işletmenin kariyer planı ile eşgüdümlü ve uyumlu olması 
Aziz Muslu, Abdülnaim Temur, "Proaktif Kariyer Adanmışlığı Davranışları Ölçeğinin Türkçeye Uyarlama ve Doğrulayıcı Faktör Analizi Çalışması”, İstanbul Gelişim Üniversitesi Sosyal Bilimler Dergisi, 8 (1), Nisan 2021, ss. $15-28$

gerekmektedir. Günümüz koşullarında klasik kariyer anlayışı kendini proaktif kariyer anlayışına bırakmıştır. İnsan kaynakları yöneticileri için çalışanların ve adayların kariyer adanmışlığı önemlidir. $\mathrm{Bu}$ adanmışlık mesleki eğitim süreci ile başlamaktadır. Günümüzün rekabet koşulları proaktif bir kariyer yönetimini zorunlu kılmaktadır. Her meslek grubunda olduğu gibi denizcilik mesleğinde de mezun olur olmaz iş bulup zaman içinde yükselmek gibi klasik bir kariyer yolu bulunmamaktadır. Meslek eğitiminden başlayarak kariyerin ilerleyen dönemlerinde proaktif bir kariyer davranışı göstermek gerekmektedir. Bu bağlamda Proaktif kariyer davranışlarını ölçmek amacıyla güvenilir ve geçerli bir ölçek ihtiyacı ortaya çıkmıştır. Hirschi ve arkadaşlarının (2014) oluşturduğu dokuz ifadeden oluşan ölçek, dil uzmanlarının önerileri doğrultusunda net ve anlaşılır hale getirilmiştir. Alanla ilgili uzmanların olumlu değerlendirmeleri neticesinde ölçek son halini almıştır. Araștırma kapsamında, sosyal ağlar ve elektronik posta yoluyla Deniz Ulaştırma İşletme Yönetimi bölümünde öğrenim gören Türkiye genelindeki 281 öğrenciye ulaşılmıştır. Bu şekilde geleceğin çalışan adayları olan denizcilik öğrencilerine proaktif kariyer davranışlarını ölçen ölçek uygulanmıștır. Yapılan çalıșmada ulașılan bulgular, araştırma sorusuna cevap olarak "The Career Engagement Scale" dokuz maddede oluşan ölçek model uyum indekslerine göre uyum göstermiş yapı geçerliliğine sahiptir. Ulaşılan model uyum indekslerine göre, kariyer adanmışlık ölçeğinin dokuz maddelik Türkçe formu dil olarak Türkçeye uyarlanmış yapı geçerliliği doğrulanmış güvenilir bir ölçek olduğu tespit edilmiştir. Amos 21 yapısal eşitlik modeli ile doğrulandığını ölçeği geliştiren Hirschi ve arkadaşlarının da (2014) önerdiği üzere, ölçek yapı geçerliği ile ilgili daha büyük ölçeklerde başka meslek gruplarına veya denizciliğin başka alanlarında kariyer hedefleyen kitle ve gruplara uygulanabilir. Kariyer adanmıșlığını etkileyebilecek diğer değișkenler ile nasıl yordalandığı analiz edilebilir. Eğitim durumu yaș, kuşaklar, sosyal statü, memleket veya mezun olunan okullar gibi değişkenler açısından tekrarlı ölçümler yapılabilir. Lise öğrencileri ve üniversite öğrencilerinin kariyer adanmışlığını ölçebileceği doğrulanmıştır.

\section{KAYNAKÇA}

AKGÜL, A. (1997). Tıbbi araştırmalarda istatistiksel analiz teknikleri. Ankara: Yükseköğretim Kurulu Matbaası.

AYTAÇ, S. (2005). Çalışma yaşamında kariyer yönetimi planlaması gelişimi ve sorunları. Bursa: Ezgi Kitabevi.

BARRICK, M., ve MOUNT, M. (1993). Autonomy as a Moderator of the Relationships Between the Big Five Personality Dimensions and Job Performance. Journal of Applied Psychology, 78(1), 111-118.

BARUCH, Y. (2004). Managing careers: theory and practice. Harlow, United Kingdom: Financial Times/Prentice Hall/Pearson.

BATEMAN, T. S. ve CRANT, J. M. (1993). The proactive component of organizational behavior: A measure and correlates. Journal of Organizational Behavior, 14(2), 103-118

BAYRAKTAROĞLU, S. (2003). Insan kaynakları yönetimi. Sakarya: Sakarya Kitabevi.

BROWN, D. J., COBER, R. T., KANE, K., LEVY, P. E., ve SHALHOOP, J. (2006). Proactive personality and the successful job search: A field investigation with college graduates. Journal of Applied Psychology, 91(3), 717 
Aziz Muslu, Abdülnaim Temur, "Proaktif Kariyer Adanmışlığı Davranışları Ölçeğinin Türkçeye Uyarlama ve Doğrulayıcı Faktör Analizi Çalıșması”, İstanbul Gelişim Üniversitesi Sosyal Bilimler Dergisi, 8 (1), Nisan 2021, ss. 15-28.

CEVHER. E (2015). Üniversitelerde Kariyer Planlama Faaliyetleri Ekseninde Kariyer Merkezlerine Yönelik Bir Araştırma, Karabük Üniversitesi Sosyal Bilimler Enstitüsü, Cilt 5, Sayı 2, s.164-177

COETZEE, M. ve SCHREUDER D. (2017). Proactive career self-management: exploring links among psychosocial career attributes and adaptability resources, South African Journal of Psychology, Volume: 48 issue: 2, page(s): 206-218 https://doi.org/10.1177/0081246317719646

COLE, D. A. (1987). Utility of confirmatory factor analysis in test validation research. Journal of Consulting and Clinical Psychology. 55(4). 284-594. doi: 10.1037/0022-006X.55.4.584 Willey.

DE CENZO, D. A. - ROBINS, S. (1996). Human resource management. New York:

EBBERWEIN, C. A., KRIESHOK, T. S., ULVEN, J. C. ve PROSSER, E. C. (2004). Voices in transition: Lessons on career adaptability. The Career Development Quarterly, 52, 292308.Series in Management. Yayınları.

ERDOĞMUŞ, N. (2003). Kariyer geliştirme kuram ve uygulama. Ankara: Nobel

ERSEN, H. (1996). Toplam kalite ve insan kaynakları yönetimi ilişsisi. İstanbul: Yön Matbaacıllk.

FERREIRA, N. (2012). Constructing a psychological career profile for staff retention. Unpublished Doctoral Dissertation. University of South Africa.

GRANT, A.M. ve ASHFORD, S., (2008). The Dynamics of Proactivity at Work. Research in organiza- tional Behavior, 28, 3-34.

GUPTA, V.K. ve BHAWE, N.M. (2007), "The influence of proactive personality and stereotype threat on women's entrepreneurial intentions", Journal of Leadership and Organizational Studies, Vol. 13 No. 4.

HALL, D. T. ve MIRVIS, P. (1995). The new career contract: Developing the whole person at midlife and beyond. Journal of Vocational Behavior, 47, 269-289.

HALL, D. T. (2002), Careers in and out of organizations. CA: Sage Publications.

Harvard Business Review. Kariyer yönetimi. M. Çetinbakıș, (Çev.), (2004).

İstanbul: Türkiye Metal Sanayicileri Sendikası Yayını

HANDY C. (1998). Ruhun Arayışı Kapitalizmin Ötesi: Ruhun Amaç Arayışı, çev. Nurettin Elhüseyni, Boyner Holding Yayınları, İstanbul.

HIRSCHI, A. (2010). The role of chance events in the school-to-work transition:

The influence of demographic, personality and career development variables. Journal of Vocational Behavior, 77, 39-49.

HIRSCHI, A., LEE, B., PORFELI, E. J. ve VONDRACEK, F. W. (2013). Proactive motivation and engagement in career behaviors: Investigating direct, mediated, and moderated effects. Journal of Vocational Behavior, 83(1), 31-40. Doi

10.1016/j.jvb.2013.02.003

HIRSCHI, A. ve FREUND, P. A. (2014). Career engagement: Investigating intra individual predictors of weekly fluctuations in proactive career behaviors. The Career Development Quarterly, 62(1), 5-20.

HIRSCHI, A., FREUND, P. A. ve HERMANN, A. (2014). The career engagement scale: Development and validation of a measure of proactive career behaviors. Journal of Career Assessment, 22(4), 575-594.

JÖRESKOG, K. ve SÖRBOM, D. (2001). LISREL. Mooresvile: Scientific Software.

KALAFAT T. (2019). Algllanan Kariyer Engelleri (AKE) Ölçeği'nin Türk Kültürüne Uyarlama Çalıșması, Kariyer Psikolojik Danışmanlığı Dergisi, 2(2), 103-124.

KIM, B., JANG, S. H., JUNG, S. H., LEE, B. H., PUIG, A., ve LEE, S. M. (2014). A Moderated Mediation Model of Planned Happenstance Skills, Career Engagement, Career 
Aziz Muslu, Abdülnaim Temur, "Proaktif Kariyer Adanmışlığı Davranışları Ölçeğinin Türkçeye Uyarlama ve Doğrulayıcı Faktör Analizi Çalıșması”, İstanbul Gelişim Üniversitesi Sosyal Bilimler Dergisi, 8 (1), Nisan 2021, ss. 15-28.

Decision Self-Efficacy, and Career Decision Certainty. The Career Development Quarterly, 62(1), 56-69. doi: 10.1002/j.2161-0045.2014.00070.x

KLEHE, U. C., ZIKIC, H., VAN VIANEN, A. E., KOEN, J. ve BUYKEN, M. (2012). Coping proactively with economic stress: Career adaptability in the face of job insecurity, job loss, unemployment and underemployment. Research in Occupational Stress and Well-Being, 10, 131-176.

KOEN, J., KLEHE, U. C., VAN VİANEN, A. E., ZİKİC, J. ve NAUTA, A. (2010). Jobsearch strategies and reemployment quality: The impact of career adaptability. Journal of Vocational Behavior, 77(1), 126-139.

KOZAK, M. A. (2001). Konaklama işletmelerinde kariyer planlaması. Eskişehir: Anadolu Üniversitesi Yayını.

MUSLU, A. (2008). Denizcilik sektöründe insan kaynakları yönetimi ve çalışma iliş̧kileri (Yayımlanmamış Yüksek Lisans Tezi). Marmara Üniversitesi, Sosyal Bilimler Enstitüsü, İstanbul.

MUSLU, A. (2017). Y kuşağının iş motivasyonunu artırmak için sürdürülebilir yöntemler sustaınable methods to increase job motıvatıon of y generatıons,: III. Uluslararası Girişimcilik, İstihdam ve Kariyer Kongresi, Muğla

NILES, S. G. ve HARRIS-BOWLSBEY, J. (2013). Career development interventions in the 21st century. (4th ed.). New Jersey: Pearson.

NILFOROOSHAN, P. ve SALIMI, S. (2016). Career adaptability as a mediator between personality and career engagement. Journal of Vocational Behavior, 94, 1-10.

OKAKIN, N. (2008). Kariyer yönetiminin bazı insan kaynakları fonksiyonları ile ilişkisi üzerine bir çalışma, Öneri Dergisi, Cilt 8, Sayı 30, s. 1 - 8 İstanbul.

OKAKIN, N. (2009). Çalışma yaşamında insan kaynakları yönetimi, Beta Yayınevi,

PARKER, S. K., WILLIAMS, H.M. ve TURNER, N. (2006). Modeling the Antecedents of Proactive Behavior at Work. Journal of Applied Psychology, 91(3), 636-652.

POULSSON, E.(2018) "Digitalisation is a "part of evolutionary change", Esben Poulsson, ICS, said" https://informaconnect.com/digitalisation-is-a-part-ofevolutionary-change-esben-poulsson-ics-said/ (Erişim Tarihi 05 Ocak 2020).

PEIPERL, M. - BARUCH, Y. (1997). Back to square zero: the post-corporate career. Organizational Dynamics (25). 7-22. https://doi.org/10.1016/S00902616(97)90033-4

POULSSON, E. (2018). Digitalisation is a part of evolutionary change. Erişim tarihi: 12.01.2020. https://informaconnect.com/digitalisation-is-a-part-of-evolutionarychange-esben-poulsson-ics-said/

ROGERS, M. E., CREED, P. A. ve GLENDON, A. I. (2008). The role of personality in adolescent career planning and exploration: A social cognitive perspective. Journal of Vocational Behavior, 73(1), 132-142

SAVICKAS, M. L. (2005). The theory and practice of career construction. In R. W. Lent ve S. D. Brown (Eds.). Career development and counseling: Putting theory and research to work. Hoboken: Wiley.

SAVICKAS, M. L., NOTA, L., ROSSIER, J., DAUWALDER, J. P., DUARTE, M. E., GUICHARD, J., ... ve VAN VIANEN, A. E. (2009). Life designing: A paradigm for career construction in21st century. Journal of Vocational Behavior, 75, 239-250.

SAVICKAS, M. L. ve PORFELI, E. J. (2012). Career adapt-abilities scale: Construction, reliability and measurement equivalence across 13 countries. Journal of Vocational Behavior, 80, 661-673.

SEIBERT, S. E., CRANT, J. M., ve KRAIMER, M. L. (1999). Proactive personality and career success. Journal of applied psychology, 84(3), 416-427. 
Aziz Muslu, Abdülnaim Temur, "Proaktif Kariyer Adanmışlığı Davranışları Ölçeğinin Türkçeye Uyarlama ve Doğrulayıcı Faktör Analizi Çalışması”, İstanbul Gelişim Üniversitesi Sosyal Bilimler Dergisi, 8 (1), Nisan 2021, ss. 15-28.

SULLIVAN, S. E. (1999). The Changing Nature of Careers: A Review and Research Agenda. Journal of Management. 25(3). Doi: 10.1177/014920639902500308.

THOMPSON, J. (2005). Proactive Personality and Job Performance: A Social

Capital Perspective. Journal of Applied Psychology, 90(5), 1011-1017.

YILDIRIM, V. (2000). Genel İşletmecilik. Adapazarı: Değișim Yayınları.

ZACHER, H. (2014). Career adaptability predicts subjective career success above and beyond personality traits and care self-evaluations. Journal of Vocational Behavior, 84, 21-30.

\section{Summary}

Rapid developments in technology today have reduced the number of jobs in all sectors while increasing the need for a qualified workforce. For this reason, it is possible to state that the classical career concept is entered into a process where abandonment. Promotion of candidates who have just started working life in the classical career understanding and knowledge to be shown according to today's conditions in order to rise and the qualification requirements were not expected to materialize. The fact that information capital has reached an important point has revealed the necessity of human resources to develop itself proactively every day. The qualified workforce that businesses need today consists of individuals who can keep up with the rapid changes experienced and do this in line with their career planning. Individuals who reach the right goals and objectives with career planning can find job opportunities and promotion opportunities. The maritime sector, which was affected later than the developments compared to other sectors and this sector has entered into a faster change process with the industry 4.0 revolution. Maritime is a profession where employees leave the profession at an early age due to difficult conditions. According to the minimum rigging regulations per ship the number of seafarers employed decreases day by day. In an interview with Esben Poulsson (Poulsson, 2018), President of the World Chamber of Shipping In 1966, 40 crew members were working on a 9,000 dwt ton ship. Today, he stated that the same number of crews were working on a giant container ship with a capacity of 14,000 TEU. For this reason, the seamen show that the competition in the labor market is increasing day by day. Despite the increase in ship tonnage, unmanned sea vehicle trials have increased due to automation in operations. As a natural consequence of this situation, developing and promoting a career at sea. Although there are many factors that affect this situation, seafarers' candidates do not plan their careers and the lack of commitment to the profession is shown by industry professionals as a reason. In this study, a previously developed scale was used to measure the career engagement of seafarers. The reliability and validity studies of the career dedication scale have been applied to the Maritime Transport Management Department students who will work as future captains in the maritime industry. 281 students reached via social networks and e-mail in Turkey. In the results of the analysis, a verification study was carried out with the Amos 21 structural equation model developed by Hirschi et al. According to the model fit indexes, it has been seen that the structural equation model fit values accepted in the scale literature. 